\title{
Faktor Domestik yang Memengaruhi Kebijakan Luar Negeri Iran terhadap Arab Saudi Pascaeksekusi Mati Nimr Al Nimr
}

\author{
Hilal Kholid Bajri, Akim \\ Program Studi Hubungan Internasional Fakultas Ilmu Sosial dan IImu Politik \\ Universitas Padjadjaran \\ e-mail : hilal.bajri@yahoo.com
}

\section{Abstract}

This article explains the factors that influenced Iran's foreign policy towards Saudi Arabia after Nimr Al Nimr execution in 2016. Nimr Al Nimr is a well-respected Shia cleric in the Middle East. As the country with the largest Shia population globally, Iran condemned Saudi Arabia's actions so that relations between the two countries deteriorated, even leading to the severance of diplomatic relations. The research question posed is what the domestic factors that influence the policy are? This article is based on qualitative research by interviewing several Middle Eastern experts and collecting data from documents and mass media. In analyzing the data, the writers used the theory from Mintz and DeRouen regarding three domestic factors that influence a country's foreign policy, namely economic interests, the role of public opinion, and the electoral cycle. The research finds that the foreign policy taken by Iran after the execution of Nimr Al Nimr is closely related to economic interests, especially related to the implementation of the pilgrimage; in line with the opinion of the Iranian people who highly respect Nimr Al Nimr; and consideration of the electoral cycle, where the policies taken by Rouhani affected his victory in the 2017 elections.

Keywords: domestic factor, foreign policy, Iran, Nimr Al Nimr, Saudi Arabia

\section{Abstrak}

Artikel ini menjelaskan faktor-faktor yang memengaruhi kebijakan luar negeri Iran terhadap Arab Saudi pascaeksekusi mati Nimr al-Nimr pada tahun 2016. Nimr alNimr adalah ulama Syiah yang dihormati di Timur Tengah. Iran sebagai negara dengan populasi penganut mazhab Syiah terbesar di dunia bereaksi keras atas 
tindakan Arab Saudi tersebut sehingga hubungan kedua negara memburuk, bahkan berujung pada pemutusan hubungan diplomatik. Pertanyaan penelitian yang diajukan adalah faktor-faktor domestik apakah yang memengaruhi kebijakan tersebut? Dalam riset ini, periset menggunakan metode riset kualitatif dengan pengumpulan data melalui wawancara pada sejumlah pakar Timur Tengah dan menelaah literatur, dokumen, dan media massa. Dalam menganalisis, periset menggunakan teori dari Mintz dan DeRouen mengenai tiga faktor domestik yang memengaruhi kebijakan luar negeri suatu negara, yakni kepentingan ekonomi, peran opini publik, dan siklus elektoral. Hasil riset ini adalah kebijakan luar negeri yang diambil Iran pascaeksekusi mati Nimr Al Nimr sangat terkait dengan kepentingan ekonomi, terutama terkait pelaksanaan ibadah haji; sejalan dengan opini masyarakat Iran yang sangat menghormati Nimr Al Nimr; dan pertimbangan siklus elektoral, dimana kebijakan yang diambil Rouhani berpengaruh pada kemenangannya dalam pemilu tahun 2017.

Kata kunci: Arab Saudi, faktor domestik, Iran, kebijakan luar negeri, Nimr Al Nimr

\section{Pendahuluan}

Kebijakan luar negeri merupakan kepanjangan dari kebijakan dalam negeri karena kebijakan luar negeri sangat dipengaruhi kebijakan domestik. Pandangan ini antara lain disampaikan oleh Morgenthau dalam (Morin \& Paquin, 2018:5). Dengan demikian, kebijakan luar negeri yang diambil oleh suatu negara selalu dipengaruhi oleh faktor-faktor yang ada dalam negara tersebut. Kebijakan luar negeri dapat berubahubah seiring dengan perubahan dalam faktor di dalam negeri, maupun faktor di luar negara tersebut, sebagaimana yang terjadi dalam hubungan di antara dua negara besar di Timur Tengah, yakni Iran dengan Arab Saudi.

Iran dan Arab Saudi adalah dua negara besar yang memiliki posisi penting dalam kehidupan politik dan ekonomi di kawasan Timur Tengah dan karena itu pula, kedua negara ini memiliki peran penting dalam menjaga perdamaian di kawasan. Namun sayangnya, hubungan Iran dan Arab Saudi tidak selalu berjalan baik dan cenderung fluktuatif, sehingga perdamaian di Timur Tengah masih sulit untuk diwujudkan. Hubungan Iran dan Arab Saudi sebelum terjadinya Revolusi Iran pada tahun 1979 tidak mengalami kendala yang berarti dan cenderung baik-baik saja, meskipun hubungan mereka sebelum Perang Dunia II hanya sebatas pengaturan haji ke kota-kota suci Makkah dan Madinah yang terletak di wilayah Hijaz, Arab Saudi Barat. 
Ibadah haji juga mendorong perdagangan skala kecil barang-barang asal Iran, seperti karpet, dan mulai muncul pemukiman komunitas Persia atau Iran di Jeddah. Ada sejumlah perselisihan tentang perbatasan yang mencakup beberapa ladang minyak bersama yang dinamai dalam bahasa Arab dan Persia, seperti Esfandiar / Al Louloua, Foroozan / Marjan, Farzad / Hasbah, dan Arash / Al Dorrah, namun tidak menjadi persoalan berarti yang dapat mengganggu keamanan negara dan kawasan pada saat itu (Keynoush, 2016:9)

Munculnya ketegangan antara Iran dan Arab Saudi di Timur Tengah tidak lepas dari campur tangan negara lain, seperti Amerika Serikat (AS) dan Inggris. Hal tersebut bermula pada tahun 1971, ketika pemerintah AS menerapkan Twin Pillars Policy ${ }^{1}$ yang dibentuk di bawah Doktrin Nixon. Kebijakan ini kemudian digunakan juga oleh Inggris dengan melakukan penjualan senjata ke Arab Saudi dan Iran. Kebijakan tersebut memberikan keleluasaan bagi Amerika Serikat untuk tetap menjaga kepentingannya di Teluk Persia agar dapat menghindari kontak langsung dengan Uni Soviet. Ekonomi Iran pada masa itu yang lebih baik daripada Arab Saudi, militernya yang lebih terlatih, serta kedekatannya dengan Uni Soviet, menjadikan Iran memiliki posisi penting bagi kepentingan AS. Iran pun mulai memiliki peran di kawasan Timur Tengah. Hal tersebut membuat Arab Saudi yakin bahwa pemimpin Iran pada saat itu, Shah Mohammad Reza Pahlevi, bermain mata dengan Amerika Serikat sehingga Iran mendapatkan keuntungan dari kebijakan tersebut.

Sejak saat itu, riak-riak konflik antara Iran dan Arab Saudi mulai muncul, sampai akhirnya memasuki babak baru pada tahun 1979, ketika Revolusi Islam yang dipimpin oleh Ayatullah Ruhollah Mostafavi Mousavi Khomeini, atau yang dikenal dengan Ayatullah Khomeini, berhasil menggulingkan dinasti Pahlevi. Twin Pillars Policy yang dilakukan oleh Amerika Serikat dan Inggris untuk membangun balance of power dan menjaga perdamaian antara Iran dan Arab Saudi akhirnya runtuh karena Ayatullah Khomeini menginginkan Iran yang baru terbebas dari berbagai macam pengaruh negara barat (Keynoush, 2016:10)

Ayatullah Khomeini kemudian menyerukan agar masyarakat tertindas (mustadh'afin) di negara-negara lain di Timur Tengah juga bangkit meraih hak-hak mereka. Hal tersebut tentunya membuat Arab Saudi khawatir akan terjadi pergolakan

\footnotetext{
${ }^{1}$ Twin Pillar Policy merupakan kebijakan yang diambil oleh Amerika Serikat setelah Inggris menarik tentaranya di Timur Tengah dan memberikan kemerdekaan kepada 10 negara yang dahulu dijajahnya pada tahun 1968. Tindakan Inggris membuat Amerika Serikat merasa khawatir, terlebih pada tahun tersebut, Amerika Serikat sedang berhadapan Uni Soviet, sehingga Amerika Serikat menjadikan Iran dan Arab Saudi sebagai sekutu regional yang dapat melindungi wilayah tersebut dari penyebaran pengaruh Uni Soviet (Hooglund, 1992).
} 
di dalam negeri, terutama karena Arab Saudi menganut sistem kerajaan. Sejak itu, isu Sunni dan Syiah muncul ke permukaan dan menjadi pemicu konflik. Misalnya, tak lama setelah revolusi Iran, tepatnya November 1979, terjadi kerusuhan antara kelompok Syiah di Arab Saudi Timur yang berawal dari peringatan Asyura. ${ }^{2}$ Saat itu pihak berwenang Arab Saudi berusaha membubarkan kerumunan, sehingga kerusuhan semakin menjadi dan berujung pada perusakan fasilitas umum. Arab Saudi kemudian mencurigai bahwa kerusuhan tersebut didalangi oleh Iran (Terrill, 2012:5).

Pada tahun 1987, terjadi tragedi Mekah, dimana ratusan jemaah haji Iran tewas di kota suci tersebut. Pihak Arab Saudi menyebut peristiwa itu sebagai "kerusuhan yang direncanakan" dimana para jamaah haji Iran melakukan aksi demo lalu tewas terinjakinjak dalam kerusuhan. Sebaliknya, pihak Iran menyatakan bahwa peristiwa itu adalah "pembantaian yang direncanakan" dimana aparat keamanan Saudi secara sengaja menembaki jamaah haji Iran yang sedang melakukan aksi demo (Kramer, 1996:161). Peristiwa tersebut terjadi di saat yang bersamaan dengan fase akhir perang Iran-Irak, dimana Arab Saudi (bersama negara-negara Teluk lainnya) secara terbuka memberikan dana perang kepada Irak (britannica.com). Iran mengecam keras Arab Saudi atas peristiwa Mekah 1987 dan memutuskan hubungan diplomatik dengan Arab Saudi.

Ayatullah Khomeini meninggal pada tahun 1989 dan digantikan oleh Ayatullah Khameni. Posisi kedua tokoh ini dalam sistem pemerintahan Iran adalah sebagai Wali Faqih atau Pemimpin Spritual. Sementara itu, eksekutif negara dijalankan oleh presiden yang dipilih rakyat melalui pemilu. Pada tahun 1991 (masa kepresidenan Rafsanjai), hubungan diplomatik Iran-Saudi kembali dibuka. Rafsanjani pada tahun 1998 (saat itu sudah tidak menjabat sebagai presiden) mengunjungi Saudi, antara lain untuk melakukan kerja sama di bidang minyak. Rafsanjani didampingi oleh Menteri Perminyakan Iran saat itu, Bijan Namdar Zanganeh (AP, 1998). Tahun berikutnya (1999), Presiden Iran Mohammad Khatami juga mengunjungi Saudi. Khatami merupakan Presiden Iran pertama yang melakukan kunjungan ke Arab Saudi setelah revolusi Iran tahun 1979. Kunjungan tersebut menghasilkan perjanjian kerja sama keamanan yang ditandatangani pada tahun 2001 oleh Iran dan Arab Saudi. Kedua negara juga sepakat bahwa perang harus dihindari karena memiliki konsekuensi besar bagi wilayah Timur Tengah (Takeyh, 2009:199).

Ketegangan antara Iran dan Arab Saudi kembali muncul ke permukaan pada tahun 2008, seiring dengan proses penarikan mundur tentara AS yang sejak 2003 berada di Irak. Saudi mengkhawatirkan penarikan tentara AS ini akan membuat pengaruh Iran

\footnotetext{
2 Tradisi kaum Syiah untuk memperingati duka cita wafatnya Sayyidina Husein (cucu Nabi Muhammad SAW).
} 
di Irak juga semakin membesar (50\% penduduk Irak bermazhab Syiah) Pada bulan Februari 2008, Raja Abdullah menyampaikan pesan keras kepada Menteri Luar Negeri Iran, Manouchehr Mottaki, yaitu, "Iran harus berhenti mencampuri urusan bangsabangsa Arab" (Hadzikadunic, 2019).

Sejak 2011, terjadi pergolakan di negara-negara Arab, yang dikenal dengan istilah "Arab Spring". Masyarakat di berbagai negara Arab melakukan aksi-aksi demonstrasi menuntut reformasi dan demokratisasi di negara masing-masing. Hal serupa juga muncul di Arab Saudi, namun jumlah aksi relatif minim dan hanya terjadi di kota-kota yang didiami minoritas Syiah, seperti Hofuf, Awwamiya dan Qatif. Tuntutan mereka adalah pembebasan tahanan politik (Nabarjee, 2011). Salah satu ulama Syiah yang juga melakukan aksi-aksi orasi dan protes kepada pemerintah adalah Syekh Nimr Baqir Al Nimr. Dia merupakan seorang ulama Syiah yang disegani oleh umat Muslim Syiah di berbagai negara Timur Tengah, baik di Arab Saudi sendiri, maupun Bahrain, Iraq, Iran, dan lain-lain. Nimr Al Nimr kemudian ditahan oleh pemerintah Saudi dan divonis hukuman mati pada tahun 2014 dengan dakwaan meminta bantuan negara lain yang dapat mengganggu kerajaan Arab Saudi (BBC, 2016a).

Dalam merespons vonis ini, Kementerian Luar Negeri Iran secara resmi memanggil (summoned) perwakilan Arab Saudi (charge d'affaires) di Iran untuk meminta penjelasan dan Iran menyatakan protesnya atas vonis tersebut (BBC, 2016a). Namun akhirnya Nimr Al Nimr tetap dieksekusi mati pada tanggal 2 Januari tahun 2016 bersamaan dengan 37 tahanan lainnya (BBC, 2016a). Eksekusi mati terhadap Nimr Al Nimr menuai berbagai aksi protes dari kalangan Muslim Syiah di berbagai negara, antara lain Bahrain, Lebanon, Irak, Kuwait, dan di Saudi sendiri. Di Iran, aksi protes dilakukan massa di depan Kedutaan Besar Saudi di Teheran. Arab Saudi memutuskan hubungan diplomatik dan menghentikan penerbangan ke dan dari Iran. Lalu, pada tahun 2016, Iran juga batal mengirimkan jamaah hajinya ke Arab Saudi. Iran menyatakan bahwa penyebab pembatalan tersebut karena kendala seputar penerbitan visa dan pengaturan keamanan untuk haji dari pihak Arab Saudi (BBC, 2016b).

Riset mengenai kebijakan luar negeri Iran terhadap Arab Saudi telah banyak dilakukan oleh para penstudi Hubungan Internasional, seperti Park \& Ward, 1979; Amiri, 2010; Amiri et al, 2011; Jiraroj Mamadkul, 2017; Rezaei, 2018. Berbeda dengan studistudi terdahulu yang lebih membahas mengenai kebijakan luar negeri Iran terhadap Arab Saudi dalam persoalan haji, energi, dan dinamika hubungan kedua negara tersebut, dalam riset ini, artikel ini lebih berfokus pada faktor-faktor domestik yang memengaruhi kebijakan luar negeri Iran terhadap Arab Saudi, khususnya setelah Arab Saudi mengeksekusi mati Syekh Nimr Al Nimr. Riset ini dilakukan dengan metode kualitatif, dengan melakukan pengumpulan data melalui wawancara dan studi literatur. 


\section{Faktor Domestik dalam Kebijakan Luar Negeri}

Dalam merumuskan kebijakan luar negeri, negara tidak hanya dipengaruhi oleh faktor eksternal/internasional saja, tetapi dipengaruhi juga oleh faktor domestik yang memiliki peran terpenting dalam keputusan yang akan diambil. Mintz dan DeRouen (2010) menjelaskan bahwa ada empat faktor domestik yang sangat berpengaruh dalam kebijakan luar negeri suatu negara, yakni, taktik pengalihan (diversionary tactics), kepentingan ekonomi (economic interest), peran opini publik (the role of public opinion), dan siklus elektoral (electoral cycles).

Karena keterbatasan ruang, dalam artikel ini penulis akan membahas tiga faktor domestik saja, Pertama, kepentingan ekonomi merupakan salah satu motif terbesar dalam kebijakan luar negeri yang diambil sebuah negara. Misalnya, negara-negara yang membutuhkan minyak, akan melakukan kebijakan luar negeri yang selaras dengan kebutuhan tersebut dan lewat kebijakannya, kebutuhan tersebut dapat dicapai. Kebijakan luar negeri hadir sebagai salah satu sarana bagi negara untuk dapat mengatasi kekurangan yang ada di dalam negaranya, seperti dengan kegiatan impor. Selain itu negara juga dapat memajukan usaha yang dijalankan oleh rakyatnya dengan memaksimalkan kegiatan ekspor produknya ke luar negeri. Kedua, opini publik juga dapat memengaruhi kebijakan luar negeri, seperti pengerahan militer, stabilitas, pemutusan hubungan, dan lainnya. Randle (1973) dalam penelitiannya mengungkapkan bahwa opini publik dan legislatif di dalam negeri dapat memaksa pengambil keputusan untuk berdamai. Misalnya, dalam konflik di Indocina pada tahun 1950-an, publik Prancis menuntut untuk diakhirinya konflik dan permusuhan tersebut (Randle, 1973; dalam Mintsz \& Derouen, 2010:132). Ketiga, siklus elektoral, yaitu proses pergantian kepemimpinan dalam suatu negara turut memengaruhi arah kebijakan luar negeri. Hal tersebut biasa terjadi ketika mendekati waktu pemilihan para pemimpin yang masih menjabat berusaha untuk tetap bertahan hidup secara politis dan bersaing dengan cara memengaruhi keputusan anggaran pada tingkat pengeluaran untuk penggunaan kekuatan, hubungan dengan negara musuh, hingga perjanjian damai (Mintsz \& Derouen, 2010:132).

\section{Faktor Domestik yang Memengaruhi Kebijakan Luar Negeri Iran terhadap Arab Saudi Pascaeksekusi Nimr Al Nimr}

Pascaeksekusi Nimr Al Nimr, terjadi ketegangan hubungan diplomatik antara Iran dan Arab Saudi. Akibat aksi demonstrasi massa di Kedubes Saudi di Teheran, pemerintah Saudi bereaksi keras dan memutuskan hubungan diplomatik kedua negara. Akibatnya, pada tahun itu (2016), jamaah haji Iran tidak bisa menunaikan ibadah haji mereka. Namun Teheran berupaya kembali mendekati Riyadh sehingga akhirnya pada tahun 
2017 Arab Saudi bersedia mengeluarkan visa untuk jamaah haji Iran. Hal ini memperlihatkan bahwa haji merupakan hal yang sangat penting bagi Teheran (Khalaji, 2017). Perkembangan terakhir, pada Februari 2021, dilaporkan bahwa para pejabat Iran dan Saudi bertemu di Baghdad dan ini merupakan pertemuan tingkat tinggi pertama pascapemutusan hubunhan diplomatik kedua negara. Pemerintah Iran menyatakan bahwa "De-eskalasi dan hubungan baik antara dua negara Islam besar di kawasan Teluk Persia sangat berguna bagi kawasan." Sementara itu, di bulan April 2021, Putra Mahkota Saudi Mohammed bin Salman menyerukan "hubungan yang baik dan khusus" dengan Tehran (AFP, 2021).

Dinamika kebijakan luar negeri Iran terhadap Arab Saudi pascaeksekusi Nimr Al Nimur tentu dipengaruhi oleh faktor-faktor domestik, sebagaimana yang akan dianalisis berikut ini.

\section{A. Faktor Kepentingan Ekonomi}

Iran dan Arab Saudi termasuk di antara negara-negara penghasil minyak dan gas terbesar di Timur Tengah. Ekonomi kedua negara juga sama-sama ditopang oleh sumber energi fosil. Nilai perdagangan antara Arab Saudi dan Iran kecil bila dibandingkan dengan ukuran ekonomi mereka. Ekspor Iran ke Arab Saudi mencapai \$158 juta pada tahun 2015, dengan produk-produk antara lain besi spons, pistachio segar dan kering, kunyit, produk setengah jadi dari besi atau baja, kismis, lantai, seng, klinker dan semen putih. Barang-barang ini merupakan $86 \%$ dari keseluruhan ekspor ke Arab Saudi. Sebaliknya, Iran mengimpor dari Saudi kendaraan, karton, botol, mineral, pupuk dan polietilen dan lain-lain, senilai dan \$45 juta (tahun 2015). Pasca eksekusi Al Nimr, pemerintah Iran menghentikan impor dari Saudi (Financial Tribune, 2016).

Kepentingan utama Iran terhadap Saudi adalah haji. Jamaah Haji Iran selalu menjadi bagian besar dari jumlah jamaah haji dunia, sejak menjalin hubungan diplomatik dengan Arab Saudi pada tahun 1929. Sejak itu juga, haji telah memegang posisi kritis dalam hubungan diplomatik antara Iran dan Arab Saudi. Sebagaimana telah dijelaskan di bagian pendahuluan, berkali-kali ketegangan terjadi antara kedua negara yang terkait dengan haji. Bahkan pascatragedi Mekah (1987), Iran memutuskan hubungan diplomatik dengan Saudi. Pasca-Perang Iran-Irak, Presiden Iran, Rafsanjani menjadikan ibadah haji sebagai prioritas utama kebijakan luar negeri Iran terhadap Arab Saudi. Hubungan diplomatik kedua negara kembali dibuka pada tahun 1991. Menteri Luar Negeri Iran pada saat itu, Ali Akbar Velayati menemui Raja Fahd pada akhir Maret 1991. Dalam pertemuan tersebut, mereka membahas dua isu utama, yakni Security Balance, dan partisipasi jamaah haji Iran. Isu haji menjadi isu pertama yang dibahas, 
karena isu yang lain menjadi lebih mudah untuk dicapai apabila isu haji dapat terselesaikan (Graham \& Wilson, 1994).

Setelah membaiknya hubungan Iran dan Arab Saudi pada tahun 1991, disertai dengan perubahan kebijakan luar negeri Iran, Arab Saudi akhirnya meningkatkan kuota jamaah haji asal Iran menjadi 115.000. Perubahan kebijakan luar negeri Iran terkait haji juga ditunjukkan oleh narasi yang disampaikan oleh Pemimpin Spritual (Wali Faqih) Iran, Ayatullah Ali Khamenei. Ketika Ayatullah Ali Khamenei menemui delegasi Iran untuk pembahasan haji dengan Arab Saudi, ia menyerukan bahwa tujuan dari ibadah haji adalah untuk menyatukan umat Islam dalam menghadapi berbagai permasalahan yang terjadi di negara-negara Islam (Fereidouni et al., 2011). Dari pernyataan tersebut, menunjukkan bahwa Iran menyerukan solidaritas untuk seluruh umat Islam, tidak dibatasi oleh mazhab.

Pemimpin Iran (baik Wali Faqih maupun Presiden) juga melarang jamaah haji mereka untuk melakukan tindakan yang tidak dibolehkan pemerintah Arab Saudi. Rafsanjani menyerukan kepada jamaah haji asal Iran untuk mematuhi aturan Kerajaan Arab Saudi dan mengendalikan diri mereka selama proses ibadah haji. Fatwa yang dikeluarkan oleh Ayatullah Ali Khamenei sangat berdampak bagi pelaksanaan haji tahun 1992. Bahkan, Ayatullah Ali Khamenei sampai mengeluarkan fatwa yang melarang jamaah haji melakkan hal-hal yang berpotensi memecah belah umat Islam. Selain itu, perwakilan Khamenei, Ayatullah Reyshahri, memimpin jamaah haji Iran dengan seruan "persahabatan, persatuan, dan persaudaraan umat Islam" (Fereidouni et al., 2011).

Membaiknya hubungan Iran dengan Arab Saudi berdampak pada meningkatnya hubungan ekonomi dan komersial antara kedua negara tersebut di masa-masa berikutnya. Presiden Iran saat ini, Hassan Rouhani juga menjadikan ekonomi sebagai prioritas utama, terlebih karena Iran sedang menghadapi sanksi AS akibat proyek nuklirnya. Dalam pidatonya di acara Forum Ekonomi Dunia pada Februari 2014, Rouhani mengatakan bahwa Iran berpotensi untuk menjadi negara dengan perekonomian terbaik di dunia, ia juga mendukung perekonomian Iran yang terbuka secara internasional. Terbukti, sejak Rouhani menjabat sebagai presiden, Iran berhasil meningkatkan perekonomiannya sebesar 2,2\% pada tahun 2015 ( Akbarzadeh \& Conduit, 2016:5). Inflasi Iran pada tahun 2015 juga berhasil turun dari 40\%, menjadi di bawah 16\%, hal tersebut tentu bagian dari kebijakan luar negeri Rouhani yang berhasil meyakinkan komunitas internasional yang terbuka terhadap investor asing (Akbarzadeh \& Conduit, 2016:5).

Namun khusus terkait isu haji, Iran menghadapi tantangan besar. Rouhani sempat memuji Arab Saudi ketika berpidato di hadapan panitia haji Iran, tepatnya pada 
bulan September 2013, ia memuji pemerintah Arab Saudi sebagai negara yang bersahabat dan saudara Iran (Miller, 2013). Akan tetapi, di tahun 2015, Rouhani mengecam Arab Saudi berkaitan dengan kecelakaan di Mina, yang menewaskan hampir 500 jamaah haji Iran, serta ratusan jamaah haji negara lain, antara lain Mesir dan Nigeria. Di tahun yang sama, juga terjadi kecelakaan jatuhnya alat berat (crane) di Masjidil Haram yang menewaskan ratusan jamaah dari beberapa negara, termasuk Iran (Fitch, A. et al. 2015). Rouhani mengkritisi kesiapan Arab Saudi dalam menyelanggarakn ibadah haji dan tidak kompetennya Arab Saudi dalam menangani korban, khususnya korban yang berasal dari Iran (Dehghan, 2015).

Kemudian pada tahun 2016, Iran mengecam eksekusi mati Nimr Al Nimr, disusul dengan kemarahan pihak Saudi atas aksi demonstran yang menyerbu Kedubes Saudi di Teheran, hubungan diplomatik kedua negara pun kembali terputus. Jamaah Iran pada tahun itu terhalang untuk menunaikan ibadah haji mereka karena sejumlah kendala termasuk hambatan visa. Namun tahun 2017, setelah melalui upaya pendekatan kedua pihak, jamaah haji dari Iran kembali bisa datang ke Saudi.

Hal ini menunjukkan bahwa bagi kedua pihak, haji memiliki nilai penting. Kehadiran jamaah haji sangat penting bagi ekonomi Arab Saudi, menurut Sola (2016) haji menjanjikan keuntungan sebesar \$12 miliar setiap tahunnya. Saat ini, jumlahnya mencapai 20 persen dari PDB non-minyak Arab Saudi, dan diperkirakan hanya akan tumbuh dengan meningkatnya lebih banyak hotel mewah di sekitar masjid suci. Dengan potensi keuntungan yang cukup besar bagi pendapatan negaranya, apabila mengalami permasalahan dengan Iran, Arab Saudi dapat kehilangan miliaran dolar dalam pendapatan dari jamaah haji asal Iran. Mengingat, Iran menyumbang angka 5\% dari dua juta jamaah haji dunia pada tahun 2015.

Sebaliknya, Iran juga mengalami kerugian ekonomi bila jamaah haji mereka dilarang (selain kerugian spiritual), karena jamaah haji Iran telah menyetorkan biaya keberangkatan ke Kepala Organisasi Iran untuk Haji dan Ziarah, serta pemerintah juga telah melakukan banyak persiapan yang membutuhkan dana. Karena itu, haji menjadi kepentingan nasional Iran dan kepentingan nasional menjadi faktor utama bagi kebijakan luar negeri Iran.

Oleh karena itu, Iran secara aktif menemui Arab Saudi untuk membahas persoalan haji dan memperbaiki hubungan kedua negara. Upaya diplomatik ini membuahkan hasil, selain kembali terbukanya jalan untuk menunaikan haji, pemerintah Saudi juga menambah kuota haji untuk Iran. Pada tahun 2017, Iran mendapatkan kuota sebanyak 86.500, mengalami peningkatan sebesar 35\% dibandingkan tahun 2015 yang hanya mendapatkan kuota sebanyak 64.000 (Shafaqna, 2017). 


\section{B. Opini Publik}

Opini publik terkait isu-isu tertentu juga dapat memengaruhi kebijakan luar negeri suatu negara. Terlebih, apabila isu tersebut merupakan isu penting yang dapat memengaruhi suatu komunitas. Dalam hal ini, eksekusi mati Nimr al-Nimr merupakan kabar pahit yang harus diterima oleh penganut Syiah di dunia. Pasalnya, Nimr al-Nimr merupakan ulama besar Syiah yang giat memperjuangkan agar sistem kerajaan yang dipimpin oleh keluarga Saud dihapus dan kesetaraan status bagi komunitas Syiah di Arab Saudi. Eksekusi mati Nimr al-Nimr oleh Kerajaan Arab Saudi pada tanggal 2 Januari 2016 memberikan dampak yang sangat besar bagi situasi perpolitikan dan keamanan di kawasan Timur Tengah. Sesaat setelah Nimr al-Nimr dieksekusi, Kedutaan Besar dan Konsulat Arab Saudi di Teheran diserang oleh ratusan orang yang berusaha untuk merusak dan membakar. Untungnya pihak kepolisian berhasil menahan 40 orang demonstran sebelum keadaan semakin parah.

Aksi demonstrasi tidak hanya terjadi di Teheran, melainkan juga terjadi di kota Mashhad yang berada di timur laut Iran. Beruntung polisi setempat berhasil menahan provokator dalam demonstrasi tersebut. Untuk meredam situasi yang mulai mengancam, Presiden Rouhani mengecam aksi penyerangan itu, bahkan menyebutnya sebagai tindakan yang tidak dapat dibenarkan. Rafsanjani turut menenangkan keadaan pada saat itu. Sementara itu Menteri Luar Negeri Iran, Ayatullah Ahmad Khatami mengatakan bahwa tetesan darah dari Nimr al-Nimr akan menodai Arab Saudi selamanya. Kecaman juga datang dari Korps Pengawal Revolusi (IRGC) yang menyebut tindakan Arab Saudi mengeksekusi Nimr al-Nimr adalah tindakan kriminal dan Arab Saudi akan merasakan balasan yang setimpal atas tindakannya. Ala al-din Boroujerdi, Kepala Majelis Keamanan Nasional dan Komite Kebijakan Luar Negeri Iran mengatakan bahwa hubungan diplomatik Iran-Arab Saudi tidak akan terwujud karena adanya eksekusi Nimr al-Nimr. Boroujerdi juga meminta kepada Menteri Luar Negeri Iran, Zarif, untuk mengurangi jumlah staf Kedutaan Besar Arab Saudi di Teheran.

Arab Saudi mengecam keras aksi demo dan perusakan terhadap kedutaan besar mereka dan segera memutuskan hubungan diplomatik. Pemerintah Iran kemudian mengirimkan surat kepada kepada Dewan Keamanan PBB Iran yang berisi penyesalan atas peristiwa ini dan menjanjikan akan mengambil tindakan untuk mencegah terjadinya kembali aksi serupa. Rouhani bahkan berjanji akan berlaku adil kepada para pelaku perusakan. Setelah itu Rouhani memerintahkan Menteri Dalam Negeri Iran untuk segera mencari dan mengadili para pelaku penyerangan tersebut (Morello \& Cunningham, 2016). 
Akhirnya lebih dari 100 orang ditangkap sebagai terduga penyerangan di Teheran dan Mashhad. Sebanyak 48 orang pelaku penyerangan akhirnya diberi hukuman tiga atau enam bulan penjara (Sharafedin, 2016). Hukuman tersebut merupakan wujud penyesalan dan pencegahan dari Iran agar aksi serupa tidak terulang kembali. Namun penyesalan Iran hanya ditujukan pada insiden perusakan Kedutaan Besar Arab Saudi saja, karena tidak ada klarifikasi atau perubahan narasi pihak Iran atas kecaman mereka terhadap Arab Saudi yang mengeksekusi Nimr al-Nimr. Dengan demikian, dapat disimpulkan bahwa kebijakan luar negeri Iran terhadap Saudi dalam kasus ini adalah menolak dan menyesali terjadinya pelanggaran diplomatik (penyerangan terhadap kedutaan asing), namun tetap sejalan dengan opini publik rakyat mereka (yang mayoritas Syiah) yang memprotes eksekusi mati atas Nimr Al Nimr.

\section{Electoral Cycles}

Sistem politik dan struktur pemerintahan Iran merupakan perpaduan yang unik dan kompleks antara pemerintahan teokratis dan demokratis. Iran adalah satu-satunya negara di dunia yang merumuskan segala kebijakan negara dengan berlandaskan ajaran Islam mazhab Syiah. Revolusi Islam pada tahun 1979 mengubah rezim lama yang berupa monarki dan membentuk struktur pemerintahan berdasarkan gagasan politik Ayatullah Khomeini pada tahun 1970, yang kemudian dinamakan Pemerintahan Islam (Hukumat e-Islami). Proses perubahan sistem tersebut tidak berlangsung cepat, namun melalui berbagai tahapan referendum. Setelah tergulingnya pemerintahan Shah Pahlevi, Ayatullah Khomeini menyatakan hanya bersedia memimpin pemerintahan Islam, sehingga ia meminta agar dilaksanakan referendum, yang akhirnya dijalankan pada tanggal 30 dan 31 Maret 1979. Dalam referendum tersebut rakyat berhak memilih untuk setuju atau tidak. Hasilnya, mayoritas rakyat (sebanyak 20.147 .855 suara atau $98,2 \%$ ) setuju membentuk negara Islam. Pengumuman hasil referendum dilakukan tanggal 1 April dan hari tersebut diperingat sebagai hari berdirinya Republik Islam Iran. Kemudian dibentuklah Badan Ulama untuk membahas Undang-Undang Dasar baru yang berlandaskan Islam dan diadakan referendum lagi, apakah rakyat setuju atau tidak dengan UUD tersebut. Meskipun hasilnya tidak sebanyak referendum pertama, namun hasil referendum tetap mayoritas setuju dengan UUD (yaitu 15.680 .329 suara) (Sulaeman, wawancara, 2020).

Sebagaimana yang telah disebutkan, sistem politik dan struktur pemerintahan Iran merupakan antara pemerintahan teokratis dan demokratis. Iran memiliki Pemimpin Spiritual (Wali Faqih) yang dipilih oleh Dewan Ulama (dan anggota Dewan Ulama dipilih melalui pemilu). Iran juga memiliki parlemen dan presiden yang dipilih rakyat melalui pemilu. Presiden Iran memiliki masa jabatanselama empat tahun dan dapat melayani 
maksimal dua periode. Presiden Iran saat terjadinya eksekusi Nimr Al Nimr adalah Hassan Rouhani yang menjadi pemenang pemilu tahun 2013 dan 2017.

Salah satu target utama Rouhani adalah reformasi kebijakan luar negeri yang ditentukan oleh tiga tema yang saling berkaitan: membangun kembali ekonomi, menyelesaikan masalah nuklir, dan mengakhiri embargo ekonomi terhadap Iran. Rouhani berusaha mendekati semua negara-negara di kawasan dan menawarkan kerja sama. Dalam pidatonya di depan Sidang Umum PBB, Rouhani menyerukan persatuan negara-negara di kawasan demi menjaga keamanan bersama (UN, 2014).

Namun, upaya Rouhani untuk mencapai target-targetnya itu mendapatkan sandungan, antara lain, kasus eksekusi Nimr Al Nimr. Rouhani dihadapkan dengan permasalahan penting yang mengharuskannya untuk bertindak, yakni ketika ulama Syiah asal Arab Saudi yang sangat terkemuka djatuhi vonis mati oleh Kerajaan Arab Saudi pada tahun 2014. Dihadapkan dengan permasalahan tersebut, kebijakan yang diambil oleh Rouhani tentu perlu sejalan dengan aspirasi rakyat Iran yang mayoritas Syiah, terlebih kebijakan tersebut juga dapat berdampak terhadap pemilihan presiden periode berikutnya (2017). Sikap yang diambil oleh Rouhani dalam kasus ini dapat menentukan kemenangannya. Selain melakukan kecaman keras atas eksekusi mati Nimr Al Nimr, Rouhani bahkan melakukan embargo ekonomi dan menghentikan impor dari Saudi.

Dalam pemilu 2017 akhirnya Rouhani kembali terpilih sebagai presiden. Saat itu, Rouhani merupakan satu-satunya calon yang berasal dari golongan moderat, sedangkan sisanya berasal dari golongan konservatif. Rouhani menang dengan perolehan $57 \%$ suara. Untuk membuktikan apakah kemenangan Rouhani terkait dengan kebijakan luar negeri Rouhani kepada Arab Saudi, penulis mencoba membandingkan perubahan suara di basis-basis konservatif di Iran.

Dalam pemilu tahun 2009 dimana persaingan antara golongan konservatif dan golongan moderat sangat terlihat jelas, karena kedua kubu masing-masing hanya memiliki satu kandidat yang sama-sama kuat, pemilu dimenangkan oleh konservatif. Ahmadinejad dari kubu konservatif menang dengan perolehan suara sebesar $63 \%$, sedangkan Mousavi hanya memperoleh suara sebesar 34\%.

Dalam gambar berikut ini, terlihat daerah mana saja di Iran yang dikuasai oleh kubu konservatif (memilih Ahmadinejad) pada pemilu Iran tahun 2009. 


\section{Gambar 1. Hasil Perolehan Suara Pemilu Iran Tahun 2009}

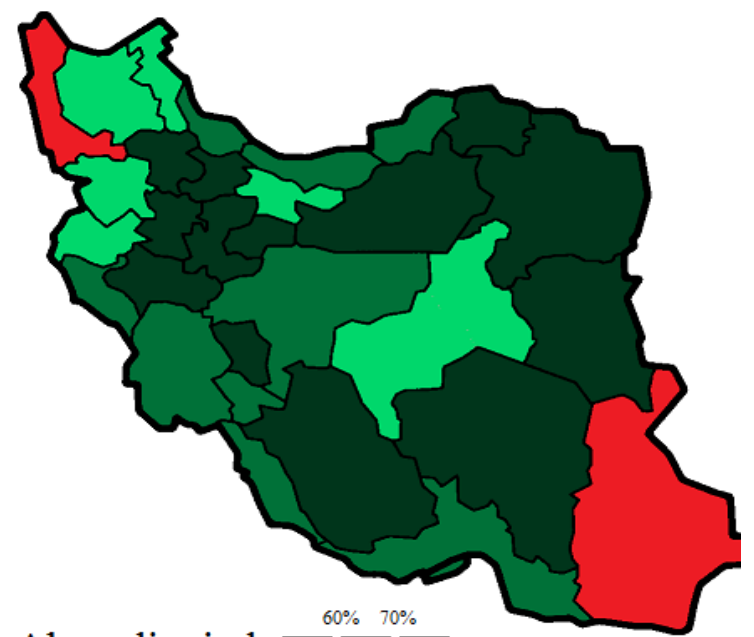

Ahmadinejad

$60 \% \quad 70 \%$

Mousavi

Sumber: Kireev (2009)

Sementara itu, pada pemilu tahun 2017, hampir seluruh bagian yang dulunya dikuasai golongan konservatif beralih dikuasai oleh golongan moderat. Dalam gambar berikut ini dapat dilihat peta persebarannya.

\section{Gambar 1. Hasil Perolehan Suara Pemilu Iran Tahun 2017}

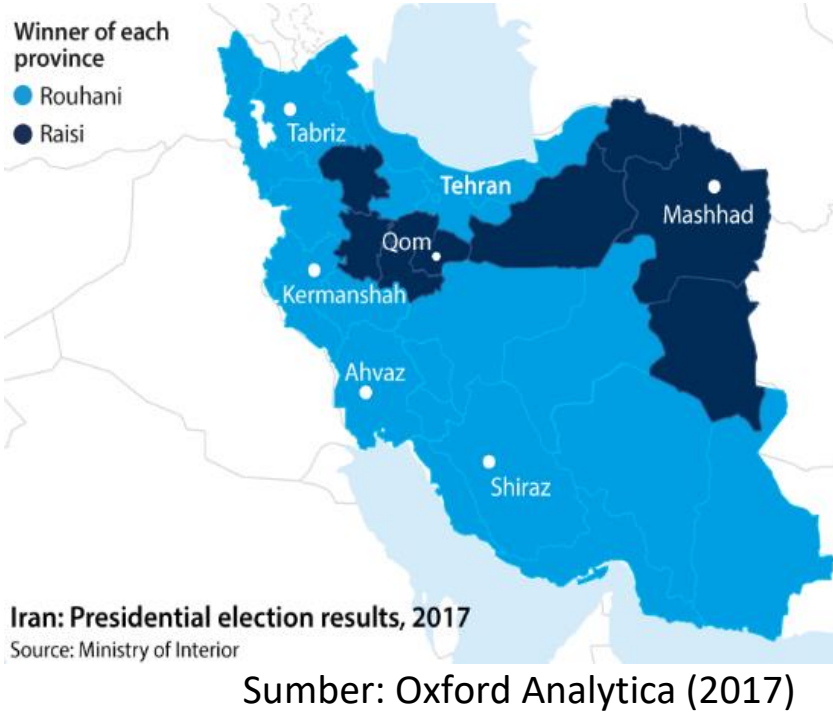


Mengingat besarnya penghormatan rakyat Iran terhadap Nimr Al Nimr, dapat diduga bahwa salah satu sebab naiknya dukungan terhadap Rouhani di wilayah-wilayah basis konservatif di Iran terkait dengan kebijakan luar negeri Rouhani yang sangat tegas mengecam Saudi atas eksekusi mati Nirm Al Nimr. Sikap Rouhani ini merupakan sikap yang diharapkan oleh rakyat Iran karena menunjukkan pembelaan kepada ulama yang mereka hormati. Akan tetapi sikap Rouhani yang lantang terhadap Arab Saudi dapat juga sebagai salah satu bentuk pencitraan dirinya sebelum menghadapi kontestasi pemilihan presiden pada tahun 2017 karena sebelumnya, Rouhani berjanji akan membawa Iran kepada kebijakan luar negeri yang mengedapankan perdamaian dan dialog. Namun dalam menyikapi kasus Nimr Al Nimr, Iran di bawah pimpinan Rouhani menunjukkan sikap konfrontatif.

\section{Simpulan}

Hubungan Iran dan Arab Saudi sebenarnya dibangun di atas prinsip saling menghormati kedaulatan negara masing-masing. Dalam perjalanannya hubungan kedua negara berjalan dengan baik. Akan tetapi, faktor-faktor yang bersumber dari internasional maupun domestik turut memengaruhi kebijakan luar negeri antara kedua pemerintahan ini, sehingga hubungan keduanya menjadi sangat fluktuatif. Ada masamasa dimana Iran dan Saudi saling memutuskan hubungan diplomatik.

Kebijakan luar negeri sebuah pemerintahan umumnya dipengaruhi oleh dua faktor, domestik dan eksternal. Dalam artikel ini dibahas faktor domestik yang memengaruhi kebijakan luar negeri Iran terhadap Arab Saudi pascadijatukannya vonis mati atas ulama Syiah terkemuka di Timur Tengah asal Arab Saudi, Nimr Al Nimr. Kebijakan yang diambil Iran adalah melakukan kecaman keras atas eksekusi mati Nimr Al Nimr dan bahkan melakukan embargo ekonomi dan menghentikan impor dari Saudi. Iran pada tahun 2016, tahun ketika Nimr Al Nimr dieksekusi mati, menghentikan pengiriman jamaah haji karena masih berseteru dengan Saudi. Namun kemudian, pada tahun 2017, kedua negara kembali melakukan negosiasi dan pada tahun itu jamaah haji Iran dapat berangkat ke Baitullah dan bahkan kuota haji Iran ditambah oleh Saudi.

Ada 3 faktor domestik yang dianalisis untuk mengetahui penyebab kebijakan luar negeri yang diambil Iran pascaeksekusi mati Nimr Al Nimr, yaitu kepentingan ekonomi, opini publik, dan siklus pemilu. Kepentingan ekonomi Iran mendorong Iran kembali menjalin hubungan dengan Arab Saudi, terutama terkait pelaksanaan ibadah haji. Sementara itu, opini publik masyarakat Iran yang sangat menghormati Nimr Al Nimr mendorong pemerintah Iran untuk tetap mengecam dan mengambil kebijakan yang konfrontatif terhadap Saudi. Faktor ini juga terkait dengan siklus elektoral, dimana 
kebijakan yang diambil Rouhani dalam kasus ini akan berdampak pada hasil pemilu berikutnya, yaitu tahun 2017 .

\section{Daftar Pustaka}

AFP. (2021). Iran says 'good atmosphere' in talks with Saudi Arabia on restoring ties. [online]. Dalam https://www.timesofisrael.com/iran-says-good-atmosphere-intalks-with-saudi-arabia-on-restoring-ties/ [Diakses 10 Juni 2021].

Amiri, R,E., Samsu, K, H, B,K., and Fereidouni, H, G. (2011) The Hajj and Iran's foreign policy towards Saudi Arabia. Journal of Asian and African Studies, [online] 46(6), 678-690. Dalam: doi: 10.1177/0021909611417546 [Diakses 2 Januari 2021].

AP. (1998). Rafsanjani Visits Saudi Arabia. [online]. Dalam https://apnews.com/article/77430abcda25f8ce15f9d6e9368b4ae0 [Diakses 2 Januari 2021].

Banerjee, N. (2011). Saudi Arabia 'day of rage' protest fizzles. [online]. Dalam: https://www.latimes.com/world/la-xpm-2011-mar-12-la-fg-saudi-unrest20110312-story.html [Diakses 11 Februarii 2021].

BBC 2016a: Sheikh Nimr al-Nimr: Saudi Arabia executes top Shia cleric. [online]. Dalam: https://www.bbc.com/news/world-middle-east-35213244 [Diakses 17 Februari 2021].

BBC 2016b: Iran 'will not send pilgrims to Saudi Arabia' for Hajj. [online]. Dalam: https://www.bbc.com/news/world-middle-east-36277234 [Diakses 17 Februari 2021].

britannica.com. (2021). Iran-Iraq war. [online]. Dalam https://www.britannica.com/event/Iran-Iraq-War [Diakses 11 Februari 2021].

Dehghan, S, K. (2015) Rouhani Criticises Saudi Arabia over hajj crush in UN speech, The Guardian. The Guardian, [online]. Dalam: https://www.theguardian.com/world/iran-blog/2015/sep/28/rouhani-criticisessaudi-arabia-iranian-deaths-hajj-crush-un-general-assembly [Diakses 23 Januari 2021].

Fitch, A. et al. (2015). Iran Doubles Number of Iranian Dead in Hajj Stampede. Wall Street Journal, [online] Dalam: https://www.wsj.com/articles/iran-doublesnumber-of-iranian-dead-in-hajj-stampede-1443694146 [Diakses 15 Februari 2021]. 
Financial Tribune. (2016). Iran-Saudi Trade in Retrospect. [online]. Dalam https://financialtribune.com/articles/economy-domestic-economy/33819/iransaudi-trade-in-retrospect [Diakses 18 Februari 2021].

Graham, D. F. and Wilson, \& P. W. (1994) Saudi Arabia: The Coming Storm, Saudi Arabia: The Coming Storm. New York: Sharpe.

Hadžikadunić, E. (2019) Insight 215: Iran-Saudi Ties: Can History Project Their Trajectory? [online] Middle East Institute National University of Singapore. Dalam: https://mei.nus.edu.sg/publication/insight-215-iran-saudi-ties-can-history-projecttheir-trajectory/ [Diakses 26 Februari 2021].

Hooglund, E. (1992). The Persian Gulf. In P. Schraeder (Ed.), Intervention into the 1990s: U.S. Foreign Policy in the Third World. Boulder, Colorado: Lynne Rienner.

Keynoush, B. (2016). Saudi Arabia and Iran Friend or Foes? New York: Palgrave Macmillan.

Khalaji, M. (2017). Ideology Outweighs Diplomacy in Iran's Hajj Decision. [online] Washington Institute. Dalam: https://www.washingtoninstitute.org/policyanalysis/ideology-outweighs-diplomacy-irans-hajj-decision [Diakses 10 Juni 2021]

Kireev, A. (2009). Iran Presidential Election 2009. Electoral Geography, [online] Dalam: https://www.electoralgeography.com/new/en/countries/i/iran/iran-presidentialelection-2009.html [Diakses 10 April 2021].

Kramer, M. (1996). Arab Awakening and Islamic Revival. New Brunswick: Transaction Publisher.

Mintz, A. and DeRouen, K. (2010) Understanding foreign policy: Decision making. Cambridge: Cambridge University Press.

Miller, E. (2013). Rouhani to forgo Hajj, Tehran official says. The Times of Israel, [online]. Dalam: https://www.timesofisrael.com/rouhani-to-forgo-hajj-tehran-official-says/ [Diakses 22Januari 2021].

Morin, J. F., \& Paquin, J. (2018). Foreign policy analysis: A toolbox. London: PalgraveMacmillan

Morello,C., \& Cunningham, E. (2016). Iran's president labels attackers at Saudi Embassy criminals. The Washington [online]. Dalam: https://www.washingtonpost.com/world/iraq-offers-to-mediate-in-saudi-iransplit-amid-fears-of-pending-disaster/2016/01/06/fd3cf816-b40c-11e5-8abcd09392edc612_story.html [Diakses 22 Februari 2021]. 
Oxford Analytica Daily Brief. (2017). Iran: Presidential election results. [online]. Dalam: https://dailybrief.oxan.com/Analysis/GI221838/Iran-Presidential-election-results2017 [Diakses 10 April 2020].

Shafaqna (2017). Saudi Arabia ups Iran's Hajj quota by 35 percent. [online]. Dalam: https://en.shafaqna.com/46241/saudi-arabia-ups-irans-hajj-quota-by-35-percent/ [Diakses 17 March 2020].

Shahram, A., \& Dara, C. (2016). Iran in the world: President Rouhani's foreign policy. New York: Palgrave Macmillan

Sharafedin, B. (2016). Iran court issues verdict for suspects in Saudi embassy attack. Reuters, [online]. Dalam: https://www.reuters.com/article/us-iran-saudi-trial/irancourt-issues-verdict-for-suspects-in-saudi-embassy-attack-idUSKBN12W3T1 [Diakses 17 Januari 2021].

Sola, K. (2016). Breaking With Iran Could Cost Saudi Arabia Billions in Revenue From Pilgrim. Forbes, [online]. Dalam: https://www.forbes.com/sites/katiesola/2016/01/05/saudi-arabiairan/\#4d9839b94c35 [Diakses: 9 April 2020].

Sulaeman, D, Y. (2020). wawancara, Bandung. Direktur Indonesia Center for Middle East Studies.

Takeyh, R. (2009). Guardians of the Revolution: Iran and the World in the Age of the Ayatollahs. Oxford: Oxford University Press

Terrill, W. A. (2011). The Saudi-Iranian rivalry and the future of Middle East security. [online] Army War College. Dalam: https://publications.armywarcollege.edu/pubs/2167.pdf [Diakses 22 Februari 2021].

UN, (2014). Summary of HE Hassan Rouhani Speech. [online] Dalam: https://gadebate.un.org/en/69/iran-islamic-republic [Diakses 4 Januari 2021]. 